\title{
浅谈中小企业的经营战略管理
}

\author{
田春燕 \\ 广西交通职业技术学院 \\ DOI:10.32629/ej.v2i4.197
}

[摘 要] 企业的战略定位是企业发展的根基所在, 具有前瞻性和预见性的营销战略能为企业在生产决策的关键时刻起到指导 性作用。作为企业在复杂多变的市场环境中竞争和发展的决策基础,经营管理战略对于任何一个企业都是非常重要的,是实现 中小企业的远景和目标的最有效的方法和基础。然而中小企业经营战略的构建还存在诸多问题,包括战略定位不够准确,经营 策略缺乏对融资问题的考虑, 内部控制建设工作不到位以及经营策略缺乏创新。基于此,文章就中小企业的经营战略管理进行 了分析。

[关键词] 中小企业; 经营战略; 问题

\section{1 中小企业的特点}

1. 1 中小企业的组织者

由于历史原因, 我国的中小企业多是家族企业, 其管理 者多数是农民阶层出身, 接受知识教育的比较少, 因而缺乏 系统、专业的经营管理经验, 在管理决策时主观臆断性比较 强, 并且追踪市场的信息意识较差。除此之外, 他们在选择员 工时往往任人唯亲, 不能客观公正的吸纳人才。

\section{2 劳动者}

由于中小企业经营规模小、技术含量的特点, 大多数企 业是以劳动密集型产业为主, 为了降低成本, 所需的劳动力 基本上都是没有经过专业训练的人员, 素质比较低。

\section{3 基础设备}

由于资金短缺等问题, 中小企业的设备大多比较陈旧, 因此在利用资源时, 效率低且浪费严重, 严重违背了可持续 发展的战略的内涵。

\section{2 中小企业在国民经济中的作用}

在中国, 支持和发展中小企业是一项长期、稳定的基本 政策。中小企业作为社会主义初级阶段市场经济的一部分, 是国民经济的重要组成部分, 是我国公有制经济制度下对市 场有力而灵活的补充, 起到了促进市场竞争、企业及商品的 多元化等必不可少的作用。如果大企业是代表一个国家经济 实力的 “砖头石料”, 那么中小企业的发展则是代表一个国家 体制活力的 “水泥砂浆”。国家的竞争力不仅体现在大企业, 同时也体现在中小企业身上, 两者功能互补, 缺一不可。发展 与大企业配套服务的中小企业是提升大企业实力和竞争力的 重要保证, 大企业的发展离不开中小企业的帮助。大中型骨干 企业体现国家实力, 成千上万的中小企业则为经济注入活力。 党中央和国务院提出了 “抓大放小” 的方针, “抓大” 和 “放 小” 缺一不可。

\section{3 中小企业经营战略的现状分析}

中小企业作为我国国民经济的重要组成部分, 中小企业 的发展对于经济发展而言其意义十分重大。中小企业的经营 类别涉猎广泛, 分布于各行领域, 因此重视中小企业的发展
建设对带动我国经济整体发展具有促进作用。通过调整制定 完善的经营战略促进中小企业步入专业模式和合作模式的 发展方向, 通过资源整合提高资源的利用率, 形成严谨系统 的产业结构。经营策略对于企业的长远发展具有指示性作用, 然而目前部分企业并没有意识到经营策略的重要意义。中小 企业更注重短期的收入和季度性的盈利, 却忽视了长远的投 资和发展, 导致目前大多数中小企业的经营状况看起平稳, 实际其发展现状一直停滞不前。

首先, 目前部分企业开始重视对自身发展的规划, 但其 经营策略不具备前瞻性和预见性。企业的经营策略应该根据 企业的综合实力、产品结构、市场发展现状和未来走向预测 进行设计, 只有基于对大数据的把握才能从根本上用经营战 略引导企业未来发展。其次, 由于管理者和企业所有者对经 营战略的漠视, 导致企业经营战略处于有名无实的状态中, 企业发展没有按照经营战略执行。对于资金有限、技术有限 的中小型企业而言, 集中兵力, 走专业化路线尤为重要, 然而 企业管理者没有考虑到产品管理和性能等因素, 加重了企业 的运营负荷。另外, 当下市场经济变化莫测, 以不变应万变成 为必然趋势。企业的经营策略关乎企业的生死存亡, 在保持 大的既定目标不变的情况下, 企业根据市场的发展方向和顾 客需求进行适当的产业调整。然而当下大部分中小企业的经 营战略一成不变, 在多变的市场环境下备受重创。

\section{4 中小企业采取的经营战略分析}

4. 1 “小而专、小而精” 战略

这是一种根据中小企业规模小、资源有限的特点而制定 的战略, 中小企业实力较弱往往无法经营多种产品以分散风 险, 但可以集中力量, 通过选择能使企业发挥自身优势的细 分市场来进行专业化的经营。采用这种战略的优点是: 第一, 中小企业可以通过扩大生产批量、扩大专业化程度和产品质 量, 提高规模经济效益; 第二, 随着需求多样化和专业化程度 的提高, 大企业也需要这些专业化程度高、产品质量好的中 小企业为其提供配套产品; 第三, 经营目标的集中, 有利于中 小企业提高管理水平和技术水平。 
选择这种战略往往过分依赖于某种产品或技术,一旦市 场变化, 需求下降就会给中小企业的生存带来威胁。首先要 确定目标市场。通过市场调研, 将某一特定的细分市场对企 业的要求同企业自身的素质相比较, 找到能够发挥自己优势 的目标市场。其次需要提高企业技术创新能力。通过与科研 机构和大专院校的联合或技术引进等多种方式, 提高企业的 技术创新能力, 不断开发新产品和新工艺, 以产品优势或成 本优势来满足消费者的需要。最后是加强市场营销。采用这 种战略的企业面临的市场或顾客一般比较稳定, 所以市场营 销的重点是增加销售渠道、加强与经销商的合作寻求新的顾 客、采用灵活的价格策略等。

\section{2 虚拟经营}

虚拟经营实质上是借用、整合外部资源以提高企业竞争 力的一种资源配置模式。在这种模式下, 企业可获得诸如生 产、设计、营销等功能, 但却不一定要拥有与上述功能相对 应的实体组织。虚拟经营注重对资源的利用，而不是控制资 源, 它追求的是尽量弱化实体组织结构形式, 最大限度地利 用外部资源, 达到全方位 “借力造势” 的目的, 其显著特点之 一是相关企业仍保持独立法人地位。因此, 虚拟经营对中小 企业的发展有杜杆作用, 其结果是使现代企业的组织结构与 运作模式发生了根本变化, 其内向配置的核心业务与外向配 置的业务紧密相连, 形成一个关系网络, 即虚拟经济组织。企 业的运作和管理也将由 “控制导向” 转为 “利用导向”。虚 拟经营对我国中小企业而言, 其意义无疑是相当深远的。因 为对于中小企业来说, 专业化分工是中小企业虚拟经营组织 的主要联系纽带, 也是其实施虚拟经营的现实基础; 信息技 术的发展, 使中小企业的虚拟经营战略成功实施成为可能, 信息技术为中小企业铸造了一个与虚拟经营战略对接的全 新平台; 制度创新其实是虚拟经营的雉形, 是由中小企业创 造出来的一种能够变大变小的技术先进的组织形态, 是一种 典型的虚拟经营方式; 技术创新优势与大型企业等级结构复 杂及低效率投入相比, 它的驱动机制更为有效, 创新要求更 为迫切, 创新成本较低。因此, 凭借这些优势, 中小企业完全 可以利用这些虚拟经营的有利条件, 积极进行虚拟经营。

\section{3 联合竞争战略}

这是根据单个中小企业资金薄弱、生产技术水平较差, 难以利用规模效益等特点而制定的一种经营战略。中小企业 在平等互利的基础上, 结成较为紧密的联系, 取长补短, 共同
开发市场, 从而有利于自己的生存和发展。采用联合竞争战 略的中小企业的联合方式大致有两类:第一类是松散型的联 合, 企业之间仅局限于生产协作或专业化分工, 在资金、技 术、人员等方面基本没有往来。采用这种联合方式的中小企 业之间彼此约束力不强; 第二类是紧密型的联合, 企业之间 除了生产协作或分工上的联系之外, 还进行资金和销售方面 的联合，如互相持股、按股分息、互相调剂余缺、建立统一 的销售队伍等。中小企业究竟选择哪种联合方式, 应该视具 体情况而定, 不能一概而论。

\section{4 跨国经营}

改革开放以来, 我国已有相当一部分企业不同程度地走 上跨国经营的道路。然而, 进行跨国经营的企业多为国内大 型企业或集团, 中小企业在此领域虽有涉足, 却为数不多。跨 国经营涉及企业经营网络的国外延伸, 迥异的经营环境可能 导致巨大风险。中小企业规模较小、产品结构单一、人才吸 引力不大、品牌形象较弱、资金缺乏等导致其实施跨国经营 战略更为不易。一般来说, 我国中小企业跨国经营的成功率 和利润率均低于大企业和企业集团。然而, 就发达国家跨国 经营的经验来看, 从大型企业跨国经营为主转向中小企业跨 国经营是一个国家提升国际竞争力的必经阶段。

\section{5 结语}

目前中小企业的经营战略的完善面临诸多问题, 包括调 整中小企业的战略定位和经营策略, 在构建企业经营策略时 需要打破中小企业融资问题造成的限制局面, 中小企业发展 壮大后, 实力上升、地位改变了, 如果经营思想上还停留在中 小企业阶段是很危险的。成功的中小企业不仅要有适合中小 企业的经营战略, 还必须知道如何扬弃, 及时展开更加适合 较大规模企业的战略部署。

\section{[参考文献]}

[1]邱建,甘婧.浅谈新经济下中小企业经营策略[J].科技 经济市场,2014(12):40.

[2]魏朝风.市场经济条件下中小企业经营战略分析 [J]. 中国乡镇企业会计,2015(5):175-176.

[3]范瑞佳.市场经济条件下中小企业经营战略的探析 [J].品牌,2015(07):46.

[4]于金陈芳.市场经济条件下中小企业经营战略的思 考[J].商场现代化,2015(15):98-100. 